\title{
0 cuidado de si e os perigos de uma ontologia ainda sem cabimento: o legado ético-espiritual de Foucault
}

Alexandre Simão de Freitas*

\section{Resumo}

O texto discute a noção de cuidado de si, no pensamento tardio de Foucault, desdobrando uma ontologia ainda sem cabimento em nossas reflexões pedagógicas: uma ontologia do si mesmo uma noção-chave do pensamento ocidental que está na base de questões importantes como a relação entre o sujeito e a verdade. Discutimos os motivos pelos quais a tematização do si mesmo permanece como uma questão ausente dos estudos foucaultianos. Inicialmente apresentamos uma breve discussão da recepção recente do pensamento foucaultiano no campo educacional brasileiro, admitindo um novo movimento de apropriação das suas ideias, que, ao mesmo tempo, supera e amplifica as imagens cristalizadas de Foucault como um teórico do poder, um anti-humanista e um niilista nocivo à teorização educacional crítica. No segundo momento, analisamos sua analítica do cuidado, focalizando a noção de si mesmo, com o fim de extrair implicações para o debate pedagógico em torno da formação humana.

\section{Palavras-chave:}

Cuidado de si, ontologia do si mesmo, formação humana.

* Universidade Federal de Pernambuco (UFPE), Recife, PE, Brasil. alexshiva@uol.com.br 


\title{
Care of Self and the Dangers of a Ontology still no Place: the Legacy Ethical and Spiritual of Michel Foucault
}

\begin{abstract}
This paper discusses the notion of self-care, in Foucault's later thought, unfolding an ontology still not fitting in our pedagogical reflections: an ontology of yourself, a key notion of Western thought which underlies important issues such as the relationship between the subject and truth. It discusses the reasons why a discussion on the self remains absent of Foucault studies. First we present a brief discussion of the recent reception of Foucault's thinking in the Brazilian educational field, identifying a new movement of appropriation of his ideas that at the same time, surpasses and amplifies the crystallized images of Foucault as a theorist of power, an anti-humanist and a nihilist harmful to critical educational theory. Secondly, we study his analysis of care focusing on the notion of himself in order to draw implications for the pedagogical debate concerning human formation.
\end{abstract}

Keywords

Care of self, ontology of self, human formation. 


\section{Considerações Iniciais}

Atualmente não há mais dúvidas de que está em curso uma nova recepção das ideias de Michel Foucault. Uma recepção impulsionada, em grande medida, pela edição dos cursos proferidos no Collège de France, cuja publicação recente tem permitido desdobrar reflexões sobre a temática da formação humana, em articulação com múltiplos usos do seu pensamento tardio. Dentre outros, Humberto Castrillón (2003) ressalta que a genealogia ética, em geral, e a noção de cuidado de si, em particular, contribuíram para produzir insights potentes sobre os processos de subjetivação, cuja analítica vem afetando a representação que temos da pedagogia, das suas categorias e dos seus campos discursivos, embora, paradoxalmente, muitas dessas leituras estejam servindo ainda para legitimar o saber e o sujeito do saber, e não para refutá-los.

Essa situação parece guardar relação com a não problematização do sujeito do cuidado de si, ou, dizendo mais diretamente, com a noção de si mesmo implicada na ética do cuidado. Por essa razão, do ponto de vista que se pretende defender aqui, ao discutir a noção de cuidado de si, Foucault não apenas abriu uma crítica radical à pedagogia como saber: ele indicou outros modos de mover as ações educativas, desdobrando uma ontologia ainda sem cabimento em nossas reflexões pedagógicas.

O problema é que, embora as noções de sujeito e subjetividade estejam incorporadas na tradição, o mesmo não acontece com a noção de si mesmo. Essa noção-chave do pensamento ocidental está na base de questões importantes, como a relação entre o sujeito e a verdade, indicando uma compreensão do saber e da Educação, distinta da lógica normalizadora enunciada pelo próprio Foucault, na obra Vigiar e punir, segundo a qual educar se realiza pelo apoio estrito da lei e da norma, do controle e da disciplina - tudo em meio a uma pedagogia que se quer, ela mesma, saber e ciência. 0 argumento, portanto, é que, embora a tematização do si mesmo permaneça como uma questão ausente dos estudos foucaultianos $^{1}$, ela carrega elementos reflexivos importantes para a análise de alguns impasses que têm paralisado a teorização educacional.

1. Uma das razões pode estar atrelada aos impasses gerados pelo dualismo fundacionismo versus desconstrucionismo, que encapsulou a recepção do pensamento tardio de Foucault em polêmicas e aporias. 0 modo singular como Foucault foi inserido na crítica pós-estruturalista e pós-moderna (termos que pouco lhe agradavam), no campo educacional, acabou por produzir e cristalizar interpretações divergentes e discrepantes do seu pensamento. É nesse sentido que nos interessa fornecer visibilidade ao que chamamos aqui de legado ético-espiritual de Foucault. Faz parte desse legado um conjunto de textos aparentemente heterogêneos, como suas reportagens sobre o Irã, suas aulas no curso de 1982 no Collège de France, suas análises sobre a questão do Esclarecimento e o problema da revolução, mas, principalmente, seus textos proto-arqueológicos. Esse corpus vaporoso permite colocar em outras bases 0 interesse de Foucault pela Antiguidade greco-romana, não apenas esclarecendo sua autovinculação paradoxal a Kant, mas, sobretudo, delimitando o lugar da espiritualidade nos seus últimos escritos. 
Com essa percepção em vista, o presente texto desdobra-se em dois movimentos analíticos articulados. Inicialmente, apresentamos uma breve discussão da recepção recente do pensamento foucaultiano no campo educacional brasileiro, admitindo um novo movimento de apropriação das suas ideias, que, ao mesmo tempo, supera e amplifica as imagens cristalizadas de Foucault como um teórico do poder, um anti-humanista e um niilista nocivo à teorização educacional crítica. No segundo momento, analisamos sua analítica do cuidado, focalizando a noção de si mesmo apreendida no bojo do que denominaremos aqui de legado ético-espiritual de Foucault, com o fim de extrair implicações para o debate pedagógico em torno da formação humana.

\section{A reativação da noção de cuidado de si: Foucault crítico da Pedagogia}

De acordo com Gallo (2008), a influência do pensamento foucaultiano na Educação pode ser compreendida a partir dos impactos da publicação da edição brasileira de Vigiar e punir, em 1977. Nesse momento, produziram-se inúmeros trabalhos que privilegiaram a questão do disciplinamento e da normalização (Gallo, 2008, p. 153), ênfase que permanece ainda hoje como referência central nos estudos sobre a Educação. A própria imagem que se faz do pensamento de Foucault, entre os educadores e pesquisadores brasileiros, nasce dos impactos dessa recepção.

Apesar de uma segunda recepção, em meados dos anos 1990, ter enfatizado o papel das tecnologias do eu na pedagogia moderna, apenas uma pequena parte das investigações ocupou-se efetivamente do domínio da ética foucaultiana. Foi preciso esperar a publicação dos cursos proferidos por Foucault no Collège de France (19781984) para compreendermos o seu recuo histórico à Antiguidade greco-romana e o correlativo deslocamento temático em direção às relações do ser consigo. Assim, foi tão somente nessa última década que se expandiu uma série de estudos em que a noção de subjetividade é tematizada diretamente.

O problema é que, nesse mesmo momento, Foucault passou a ser acusado de individualista e liberal, por supostamente glorificar uma espécie de esteticismo amoral e apolítico. Se verdadeira ou não, essa crítica parece estar relacionada à incompreensão de um conjunto de temas que passaram a configurar o corpus foucaultiano, tais como as noções de ascese, espiritualidade, parresia e amizade, o que indica a dificuldade em lidar com os desdobramentos das temáticas imanentes à ética do cuidado de si.

Uma dessas dificuldades aparece, por exemplo, na aproximação linear dos con- 
ceitos de governo e cuidado. Vários comentadores, ao tomarem essas noções como sinônimas, produzem um viés que reduz o cuidado de si ao mero exercício de um domínio notadamente no uso das paixões e dos desejos, o que introduz um matiz utilitarista, claramente ausente na discussão que Foucault realiza em torno do cuidado de si. Nesse aspecto, seguimos Walter Koan (2011, p. 57), para quem é importante perceber que Foucault (2004), no curso A hermenêutica do sujeito, ao discutir a noção de cuidado, não se refere ao verbo árkhomai (mandar, governar), que sintetizaria a relação entre corpo e alma, e expressa poder. 0 campo semântico do cuidado (epimeleia), ao contrário, expressaria uma linha de fuga radical aos modos hegemônicos de exercício do poder, uma das razões do interesse de Foucault no tema.

Aliás, nós mesmos fomos esclarecidos das dificuldades que o próprio Foucault enfrentou, ao lidar com esse campo semântico. No curso de 1984, A coragem da verdade, na aula de 22 de fevereiro, ele expõe suas tentativas aparentemente fracassadas de investigar as origens etimológicas do termo "epimeleia”². Para organizar essa aula, Foucault solicitou a George Dumézil uma consulta sobre a raiz indo-europeia da palavra. 0 resultado da pesquisa apresentou as seguintes implicações: primeiro, parece não ser possível, afirma Foucault (2011), fornecer nenhuma indicação concreta ao sentido do termo. Segundo, na ausência de uma significação segura, tanto Dumézil quanto Foucault se puseram a levantar algumas hipóteses disparatadas, associando a raiz da noção, melos, a um conjunto de termos como melodia, canto, música. Mais sugestivas são as associações que Foucault então articulou, juntamente com o historiador Paul Veyne, admitindo que a noção guardaria relação com um canto, mas um canto de chamada. 0 exemplo fornecido é o canto do pastor para fazer regressar seu rebanho ou outros pastores. Uma espécie de canto sinal. Com base nessas ideias, Foucault resolveu assumir que a noção de epimeleia aponta para algo que nos chama, nos convoca.

Nesse contexto, ele chegou a sugerir maliciosamente, aos que se interessassem pelo problema, que haveria algo como um segredo musical, o segredo de um chamado musical na noção de cuidado. De sorte que, e isso é fundamental, sua conclusão é que, na análise dos textos acerca da ética do cuidado de si, seria necessário levar em conta certa exigência metodológica, pondo em pauta “um método de superposição das diferentes indicações formais que podemos encontrar em um texto", como um jogo de "palavras cruzadas", semelhante ao "método utilizado pelo próprio Dumézil na análise das mitologias in-

2. 0 contexto da aula é a transição entre a retomada da análise da Apologia de Sócrates, visando preparar os ouvintes para a questão dos cínicos, pela leitura de Laques (Foucault, 2011, p. 131-135). 
doeuropeias" (Foucault, 2011, p. 134). Esse método configuraria um caminho irônico para retomar o que, em um determinado discurso, texto ou acontecimento, repousa ainda como um enigma para os nossos sistemas de pensamento.

Nos termos propostos em nossa reflexão, isso significa operar com Foucault contra Foucault. Explicamos. Ao tematizar a ética do cuidado, tratamos de forma sobreposta as categorias dicotômicas presentes ao longo dos textos finais de Foucault (cuidado $x$ conhecimento, filosofia $x$ espiritualidade, psicagogia $x$ pedagogia, etc.), tornando visíveis as tensões que as articulam. Por exemplo, em uma via oposta aos comentadores que têm cindido sua análise dos textos platônicos Alcibíades e Laques, nós cruzamos essas leituras, com o fim de evidenciar um contexto comum: a crítica ao déficit da pedagogia ou o problema relativo à formação do mestre, já que é nesses âmbitos "que a produção de si se realiza em uma atitude especial de pensamento, elaborada na epimeleia como desdobramento essencial dos poderes éticos” (Fimiani, 2004, p. 104). Ao operar desse modo, colocamos em cena, no tema do cuidado de si, o caráter enigmático da noção de si mesmo, presente nas problematizações de Foucault.

Isso é importante, pois, como indica o trabalho seminal de Andrés Peña (2003), Foucault apresenta uma análise inovadora das possibilidades de formação do sujeito, tomando como ponto de partida essa noção. Assim, essa forma de análise permite destacar o que, talvez, seja o aspecto mais curioso e o mais estranho nessa reflexão do cuidado de si: o fato de a análise aparecer imbricada com questões espirituais. 0 fato de essa reflexão associar-se com uma dada condição da espiritualidade parece não ter demovido Foucault da convicção de sua importância, tanto que ele insiste na relevância de apreendermos o próprio ato de conhecer como comportando "toda a estrutura de um ato espiritual” (Foucault, 2004, p. 21). Para ele, parece não haver dúvidas de que a ideia de espiritualidade permite articular uma crítica radical ao privilégio epistemológico dado às relações entre sujeito e verdade, configurando-se como uma questão carregada de consequências também para a reflexão pedagógica.

Nessa perspectiva, a noção de espiritualidade contrapõe-se a uma visão do saber pedagógico como algo positivo, ou seja, como um saber que constrói um sujeito e um objeto e, consequentemente, tal noção não considera a pedagogia como disciplina. Apreendida pelo prisma da espiritualidade, a Educação emerge como uma arte da existência.

No limite, os problemas da Educação seriam coemergentes aos problemas da parresia, pois, ao questionar a quem cabe seu exercício, Foucault termina por discutir os exercícios necessários para impulsionar uma dinâmica formativa direcionada 
ao dizer-fazer ético. Ele mesmo questiona: qual seria, em uma Educação eticamente orientada ao dizer parresiástico, o ponto no qual se deveria pôr ênfase?

Sua tentativa de responder a essa questão não deixa de ser surpreendente. Após afirmar existir um lado desagradável, mesmo brutal, na Educação como arte de viver, Foucault conclui, defendendo que uma Educação dessa natureza colocaria em risco as instituições e os poderes vigentes, pois o trabalho pedagógico, nesse contexto, invocaria uma força capaz de aproximar professores e alunos de uma verdade que se incorpora ética e existencialmente no próprio modo de viver a relação educativo-formativa.

Nesse sentido, o próprio Foucault aparece, nesses cursos e reflexões, como um crítico ou um parresiasta da pedagogia. Por isso, diz Humberto Castrillón (2003, p 214), a obra tardia de Foucault pode ser considerada “uma obra de Bildung”. Para esse autor, Foucault poderia figurar como um pedagogo. Não um pedagogo positivo, produzido pelas instituições educativas, um teórico da Educação. Ele seria, antes de tudo, um educador que luta para criar liberdades para si e para os outros, fazendo, da sua experiência docente, ocasião de uma transformação radical nas relações que ele mesmo estabeleceu com o saber e consigo mesmo como sujeito desse saber.

\section{Entre o fim do homem e a naturalização do espírito: os perigos éticos de Foucault}

As implicações desse gesto pedagógico de Foucault ainda estão por ser dimensionadas, sobretudo em uma época na qual a Educação aparece cada vez mais como uma presa de seus próprios poderes. Nesse contexto, cabe destacar, nos processos contemporâneos de subjetivação, uma dobra específica que afirma pretensões de fundir o social, o cerebral e o mental, por meio de uma nova ciência denominada neuroeducação. Como indicam Heliane Rodrigues e Cristine Mattar (2012, p. 281), não se espera da neuroeducação, em especial, e das neurociências, em geral, a solução para problemas específicos de aprendizagem, mas o anúncio adventício de uma nova biologia da consciência ou do espírito. Argumenta-se que, abordadas fora de um contexto de especulação metafísica, seria possível lidar com essas noções como objetos estritos de experimentação científica, desdobrando-as em ferramentas de intervenção pedagógica³.

3.Nos termos de Ehremberg (2004, p. 133), é possível identificar três perspectivas no programa atual das neurociências. Do ponto de vista teórico, visa-se explicar 0 espírito em uma base naturalista que postula o cérebro como fundamento. Numa perspectiva prática, refere-se à fusão entre neurologia e psiquiatria, separadas desde 0 século XIX. No âmbito social, o cérebro torna-se um objeto de identificação, um mediador dos processos de reconhecimento subjetivo, deixando de figurar como um órgão médico-biológico, para ser alçado à condiçãa sui generis de ator social. 
O importante aqui é a identificação unívoca entre o conhecimento do cérebro e o conhecimento de si, bem como a defesa de que um agir eficaz sobre o cérebro poderia aumentar nossa capacidade de decisão e ação moral. Assim, o sucesso alcançado pelas neurociências articula-se diretamente com o estilo de resposta que elas oferecem aos problemas configurados por nosso ideal de autonomia. Do ponto de vista educacional, o "estilo neurocientífico" (Ehremberg, 2004, p. 133) incita uma série de expectativas, ao oferecer técnicas de desenvolvimento das nossas capacidades cognitivas.

Essas técnicas emergem atreladas com dinâmicas de controle emocional e social, configurando-se como elementos ativos de um programa de bem-estar e de autogerenciamento da qualidade de vida. Tudo se passa como se os modos de subjetivação antropológica estivessem sendo substituídos ou deslocados por formas de subjetivação cerebral, constituindo, nesse processo, novas formas de experiência de si.

Estaríamos, enfim, assistindo ao fim próximo do homem, anunciado por Foucault? A resposta a essa questão não é simples e pode ser mais bem apreendida mediante uma análise da noção de sujeito implicado na ética do cuidado foucaultiana, uma vez que a noção de si mesmo evoca uma reflexão seminal acerca da nossa capacidade de ter acesso a verdades. Apesar disso, essa noção perdura como algo profundamente enigmático para as pedagogias filosóficas (Dalbosco, 2010). Mesmo a busca recorrente de justificação de uma antropologia filosófica sistemática não chegou a configurar uma ontologia do si mesmo que continue uma tarefa adiada pela pedagogia.

O fato é que o tema do si mesmo figura como a pedra de toque da ética do cuidado de Foucault, pondo em questão nossas experiências concretas com a alteridade, bem como suspendendo a caracterização da subjetividade pelas determinações da substância e da presença. O desconforto gerado por essa ontologia do si mesmo pode estar relacionado a dois fenômenos inter-relacionados.

0 primeiro é a sua clara vinculação à noção de espiritualidade. Como vimos, contrariando as destinações ocidentais do pensamento, Foucault mobilizou uma reflexão que fez dessa noção algo ainda pertinente. Uma segunda razão é a sua vin-

\begin{abstract}
4. Estudos recentes acerca da análise de Foucault em torno da noção de Gemüt, na Antropologia do ponto de vista pragmático, de Kant, têm indicado caminhos até então insuspeitos na sua busca por vincular conhecimento e vida, ao mesmo tempo em que delineia as bases de uma curiosa definição de espírito, em sentido estético-experimental.
\end{abstract} culação com problemas que, aparentemente, já haviam sido superados pelo próprio pensamento foucaultiano: o projeto de contestação dos fundamentos das ciências humanas e suas críticas às questões antropológicas (Kraemer, 2011)4. 
No entanto, recentemente, alguns pesquisadores como Márcio Miotto (2011), ao debruçarem-se sobre as análises foucaultianas nos anos 1950, vêm aprofundando o contexto de produção de textos como $A$ constituição de um transcendental histórico desde a Fenomenologia do Espírito de Hegel, publicado em 1949, e O problema das ciências humanas nos pós-cartesianos, publicado entre os anos de 1950 e $1951^{5}$, que permitem tornar visível uma espécie de "conjunto problemático que segue do kantismo às ciências humanas" (Miotto, 2011, p. 08), em uma continuidade assombrosa com as análises desdobradas na sua fase ética.

A partir dessa ótica, a problematização da ontologia do si mesmo tornaria evidente uma série de fissuras, em uma linha tortuosa de elaboração conceitual, que vai de uma "teoria geral do ser humano" a uma "história das formas de experiência", redimensionando o modo como Foucault se impôs a tarefa de recusar os humanismos e evitar as antropologias, sem, contudo, afastar da sua visada crítica o esforço para uma apreensão do homem em sua singularidade concreta. A "questão antropológica" é o que permite a Foucault desvelar os problemas inerentes à "fina película do mundo ético ocidental", pela retomada vigorosa do problema da verdadeira vida (alêthê bios).

Dessa maneira, a afirmação de Foucault (2004) de que existiria algo de perturbador no princípio do cuidado de si parece guardar mais problemas do que somos capazes de balizar. Há indícios de que pode haver perigos mais sombrios reservados àqueles que se ocupam de seu pensamento tardio, tais como uma fantasmática ontologia da alma ou do espírito humano, cujas dificuldades de recepção manifestam que o problema da verdadeira vida, tema essencial para Foucault (2011, p. 147), permanece como um tema confiscado.

\section{0 problema da verdadeira vida e o legado ético-espiritual de Foucault}

A questão do si mesmo, desdobrada no âmbito do tema da verdadeira vida, indica um problema abandonado pelos nossos sistemas atuais de pensamento, pois quem conseguiria, hoje em dia, fazer qualquer referência precisa ao espírito humano? Nos termos de Claude Bruaire (2010, p. 11), o espírito, quando raramente evocado, apresenta-se como um "sinal vestigial de uma crença arcaica e frágil”. Na linguagem filosófica, o espírito figura como o emblema paradigmático de uma “recusa do real indesejável”, uma espécie de

5. Destacam-se, nessas análises, dois cursos ministrados por Foucault, respectivamente, em 1952-53 e 1954-55, intitulados Consciência do homem e reflexão transcendental e Problemas de antropologia. 
inquieto pedido de fuga, no máximo um desejo inútil do Totalmente outro em relação ao mundo desencantado. Não há dúvidas, aqui: o espírito tornou-se, no limite, uma identidade para a marginalidade simples do poeta ou do revoltado; uma espécie de energia residual, a fazer eco para uma demanda de sentido moribunda.

A reflexão sobre o espírito parece ter-se evaporado da atividade global do pensamento. Em que pese o chamado "giro teológico-político" de vários pensadores radicais, como Alan Badiou, Slavoj Zizek e Giorgio Agamben, os esforços para retomar a questão do sujeito em bases ontológicas pós-metafísicas não eliminaram o fato de que, por uma espécie de "astúcia da matéria" (Sloterdijk, 2002, p. 30), o espírito humano viu-se capturado e esgotado no fenômeno da vida, e sua liberdade, na necessidade de gestão biopolítica da espécie.

Condenado como uma má figura do pensamento, o espírito vigora tão somente onde a vida histórica aparece lesada, manifestando-se como esforço de cálculo do improvável, mediante processos sofisticados de disciplina, adestramento e regulamentação. Por que razão, então, contrariando essa destinação atual do pensamento sobre o espírito humano, Michel Foucault teria mobilizado uma reflexão original, que visa fazer dessa questão algo ainda pertinente para os debates filosóficos e pedagógicos?

Em nosso modo de ver, a resposta parece localizar-se nos próprios cursos tardios de Foucault, o que significa dizer que os textos desse período precisam ser lidos menos como uma exposição de conhecimentos histórico-filosóficos e mais como uma pragmática, ou seja, como protocolos de um exercício espiritual em andamento. Assim,

[...] ao mesmo tempo que nesses trabalhos foucaultianos se descrevem os modos de subjetivação antigos, o exercício de escrita atua como produção de modos de subjetivação, tanto para aquele que os descreve quanto para aquele que lê sobre eles. Ao ler as últimas obras, bem como os últimos cursos e entrevistas, de Foucault, compartilha-se uma atmosfera, a da espiritualidade grega, que ali pode ser captada sensivelmente (Rodrigues; Mattar, 2012, p. 289).

O problema é que, mesmo quando há o reconhecimento dos movimentos inerentes ao pensamento tardio de Foucault, as acusações perduram, sobretudo no plano da ética. Nesse aspecto, talvez seja importante relembrar o temor generalizado de 
que Foucault estivesse propondo que a verdade seria apenas uma variável dependente do modo como nossas sociedades se organizam para coibir e promover a emissão de enunciados específicos. Para os críticos, estando as relações de poder imbricadas na estrutura interna da verdade, a única opção seria abandonar toda pretensão de enunciação publicamente inteligível, já que a política da verdade confundir-se-ia com o próprio espaço do pensamento.

Esse tipo de argumentação passa ao largo do fato de os escritos éticos de Foucault apresentarem outra forma de entender nossa relação com a verdade. Trata-se, nos termos de Foucault, de colocar em análise os caminhos da "coragem da verdade". "A coragem da verdade", como sabemos, é também o título do último curso ministrado por Foucault. Nesse curso, ele suspende as análises relativas às estruturas próprias aos diferentes discursos, reconhecidos como verdadeiros em chave epistemológica, para delimitar uma análise "aletúrgica", ou seja, um "tipo de ato pelo qual o sujeito, dizendo a verdade se manifesta" (Foucault, 2011, p. 04), fazendo com que o próprio sujeito seja reconhecido pelos outros como dizendo a verdade.

Trata-se, sem dúvida, de um texto raro, na medida em que coloca a questão da verdade em outras bases de significação, postulando uma ética da verdade. Foucault faz remontar essa analítica ética da verdade ao texto platônico Laques. Nesse diálogo, ele assinala o fato de que, interrogando homens de Estado, Sócrates propõe um tipo singular de veridicção, contraposta àquela que ele havia analisado dois anos antes, ao tratar de outro texto platônico, o Alcibíades, no qual se discute um modo de ocupação com a alma que permite ao ser humano acessar a verdade sobre si mesmo.

Ao comparar os dois diálogos, vislumbra-se a emergência das duas grandes vertentes do pensamento ocidental: a filosofia como aquilo que, incitando o homem a ocupar-se consigo mesmo, o conduz à realidade metafísica, que é a da alma; e a filosofia como uma prova de vida, contribuindo para a elaboração de certa modalidade ético-estética da existência. Essas vias, contudo, não nos parecem incompatíveis ou excludentes. Foucault não pretende que exista uma contradição insuperável entre o tema de uma ontologia da alma e o de uma estilística da existência, em que pese a recepção hegemônica que tem destacado a polaridade dessas duas vias filosóficas e a consequente percepção de que a história da filosofia ocidental priorizou o polo da metafísica.

O próprio Foucault (2011, p. 149) sinaliza duas tarefas simultâneas para o pensamento contemporâneo: fazer a história da metafísica da alma e estabelecer a história da estilística da existência. A urgência dessas duas tarefas é delimitada no contexto 
da preocupação com o tema da verdadeira vida. Ao buscar responder o que é uma verdadeira vida, Foucault nos coloca em contato com quatro significados, segundo os quais algo pode ser definido como verdadeiro: o não oculto; o que não recebe nenhuma adição; o que é direito e reto; e o que se mantém idêntico e imutável. Esses quatro sentidos seriam aplicáveis não apenas a proposições, mas a maneiras de ser, de fazer, de falar, de pensar e de conduzir-se.

Desse modo, não se trata de defender uma história em detrimento da outra, uma vez que, segundo Foucault, a não tematização do problema da alma acabaria por manifestar um fenômeno inquietante: o confisco do tema e das práticas da verdadeira vida pela religião e sua absorção pela ciência. Isso seria um problema, diz Foucault (2011, p. 217), porque, nesses dois casos, o problema da verdadeira vida e do dizer verdadeiro simplesmente desapareceria. Assim, a despeito da centralidade outorgada à vida cínica, é necessária uma ressalva importante: uma polarização analítica rígida entre o Alcibiades e o Laques pode acabar por obstruir a percepção dos princípios gerais que conectam e dirigem as duas linhas de desenvolvimento do pensamento filosófico.

\section{Uma ontologia ainda sem cabimento: o si mesmo como uma questão espiritual}

Esse argumento nos ajuda a compreender por que, nos termos de Rachel Gazzola (2012, p. 12), um dos aspectos menos abordados na leitura foucaultiana do Alcibíades é justamente o ponto em que Foucault parece, ele mesmo, hesitar quanto ao uso da palavra "alma", no contexto de sua crítica ao subtítulo do diálogo: Sobre a natureza humana. Assim como o personagem Alcibíades parece perder a chance de questionar Sócrates sobre o que é efetivamente alma, como se o dito sobre ela fosse algo óbvio e já sabido, os comentadores de Foucault também parecem silenciar quanto ao modo ambivalente como ele lida com a noção muito específica de alma, enunciada por Platão nesse diálogo. A hesitação de Foucault, expressa no termo ambíguo "alma-sujeito", e o silêncio dos comentadores contribuem para obstruir o eixo modal do diálogo: os fundamentos onto-antropológicos do si mesmo, alvo das práticas do cuidado de

6. Esse aspecto do daímon é expresso com clareza no curso Coragem da Verdade, durante a primeira hora da aula do dia 15 de fevereiro de 1984, quando Foucault lembra que, no mundo grego antigo, o cuidado dos homens pelos deuses logo se tornará o cuidado dos homens, apesar dos deuses. si e da parresia. Mas por que a resistência de levar adiante essa problemática?

Para Gazzola (2012, p. 19), isso se deve ao fato de a reflexão em torno da alma girar em torno de uma figura fugidia: o daímon de Sócrates ${ }^{6}$. 
Segundo essa autora, não há dúvidas aqui: a presença do daímon coloca em jogo uma reviravolta e uma emergência na reflexão onto-antropológica ocidental. Para os interesses específicos de nossa argumentação, não é necessário seguir passo a passo o processo argumentativo que se segue ao anúncio insistente do papel formativo do daímon de Sócrates nos destinos da Educação de Alcibíades. É suficiente evidenciar que, nesse momento, Alcibíades se vê em uma "situação vergonhosa", ou seja, impotente diante de perguntas consideradas vitais ao exercício político almejado por ele. 0 embaraço amplifica-se, quando ele se vê interpelado a respeito do nome que se deve dar à arte daquele que sabe cuidar de si mesmo ou o que será bem cuidar da alma e que nome se deve dar a isso.

Obviamente, hoje em dia, nós também nos embaraçaríamos diante desse questionamento. Isso porque a paideia subjacente ao cuidado de si visa ativar uma relação singular de si a si, o que depende de certas disposições espirituais. Dizendo de forma mais incisiva: o sentido ocupado no diálogo pela presença do daímon visa recobrir uma experiência mais ampla em torno do próprio pensamento humano (Lima Vaz, 2011, p. 153). Trata-se de apontar, na experiência do pensar, o despertar de uma vontade de saber que exige o engajamento com algo que nos excede, indicando a precariedade do encontro com as verdades acerca da melhor forma de viver.

Pensar, como ato imanente ao cuidado de si, significa que temos de tomar decisões sem o amparo de uma argumentação lógico-racional, aceitando a fragilidade da nossa relação com a verdade. Nos termos de Agamben (2006, p. 125), na voz deste daímon ressoa o fundamento "sobre o qual se apoia toda a nossa cultura, a sua lógica como também a sua ética, a sua teologia e a sua política, o seu saber e a sua loucura”. O problema é que, como sujeitos esclarecidos, acreditamos poder libertar-nos de todo estado anímico excepcional ou excessivo a sustentar nossas deliberações racionais. Logo, perdemos contato com toda forma de saber que permite lidar com o ruído desarmônico, com a vertigem imposta pela presença do estrangeiro em nós. Esquecemos ou fingimos esquecer que nas fontes de nossa cultura e de nossos sistemas de pensamento oculta-se uma antropologia pneumática.

Nesse terreno, os pensadores terapeutas, de ontem e de hoje, permanecem lutando contra os estados excepcionais do ânimo e os múltiplos extravios da razão, mantendo os estados inspirados banidos dos registros da meditação filosófica?

7. Como indica Foucault (2011, p. 148), Platão incorpora, silenciando o mistério extático, ou seja, o mistério da alma que se dobra sobre si mesma, reprimindo, desse modo, o problema central da política: a política como experiência, ou seja, o "problema do que é em seu ethos, a política”. 
Teorias do conhecimento e experiências do êxtase passam a negar-se reciprocamente, e o acontecimento da verdade só acontece nos marcos de uma compreensão lógica. Como sinaliza Peter Sloterdijk (2008), nesse contexto, quase se pode dizer, a modo de definição, que um filósofo é alguém que não sabe mais o que são estados elevados de contemplação. Mas isso significa dizer também que o filósofo se tornou uma figura que não conhece a possibilidade da privação de sua própria razão.

Assim, o debate sobre o si mesmo em articulação com o problema da verdadeira vida reacende diagnósticos inquietantes, pois uma das peculiaridades dos cursos tardios de Foucault é a colocação em cena da diferença de uma tomada de palavra arriscada. Ele parece não temer uma ontologia crítica que pensa uma "paideia do espírito", escavando a contrapelo uma genealogia da alma e de nossas relações com ela. No último estágio de sua obra, Foucault recupera uma análise da existência humana, retirando-a, mais uma vez, do “domínio do cientificamente cognoscível”, liberando "nossos espíritos das categorias biológicas" que obscurecem a percepção de nós mesmos, e trazendo à tona o modo como chegamos a nos “compreender como seres humanos” (Bernauer, 1994, p. 335). Eis porque é possível concordar com Agamben (2009, p. 01), para quem o problema do nosso tempo é já não existirem problemas espirituais.

[...] que já não existam problemas espirituais, que estes já não sejam sentidos como algo de decisivo e de iniludível, gera, com efeito, uma angústia sem precedentes. Longe de nos libertar do mal-estar, o facto de os problemas da humanidade se terem tornado calculáveis, questões factuais urgentes e eventualmente complicadas, mas que, em última instância, requerem ser governadas e não vividas nem pensadas, é precisamente o que nos remete para uma especial angústia.

Para o filósofo italiano, enquanto economia, medicina e tecnologias de toda a espécie (que são sempre, em última análise, técnicas de governo) assumiram a direção dos destinos humanos, os problemas espirituais (e as técnicas que transmitiam a sua experiência: poesia, filosofia, arte) deixaram de ser decisivos.

A assim chamada espiritualidade não é senão o nome dado ao ponto de maior intensidade em cada domínio da vida. A espiritualidade remete, aqui, a uma tradição de pensamento de que quase já não há mais traço. A mesma tradição que sustenta o dito 
heraclitiano: ethos anthropos daímon. Ora, Foucault parece retomar essa tradição com o propósito claro de articular novas formas de insurreição que fundem filosofia, Educação, política e espiritualidade. Ao falar do nosso “desejo de espírito em um mundo sem espírito" (Foucault, 2010, p. 230), os textos ético-espirituais de Foucault nos deixam como seu último legado uma reserva heterotópica de mundo, perturbando os lugares-comuns dos nossos modos de viver e pensar o presente. Assim, por mais que as reflexões do Alcibíades sirvam de ponto de ancoragem ao pensamento metafísico, há nele também um topos que pouco serviu à nossa modernidade filosófica: de que maneira as nossas disposições anímicas se configuram como suportes efetivos para o nascimento de uma liberdade possível - liberdade apreendida na forma de exercício de um saber-fazer específico, conduzido pela prática filosófica vivida como um exercício espiritual.

Por mais que, aparentemente, estejamos desconectados desse caminho de pensamento, parece que o uso da palavra "espiritualidade" para caracterizar uma vida filosófica só faz sentido, se também levamos em conta suas raízes e significações na ontologia do si mesmo que a circunscreve. Por isso, recoberta por termos como "ser", “eu”, “consciência”, “cérebro" e "sujeito”, a noção de si mesmo como instância espiritual ainda aguarda um lugar à altura em nossas pedagogias críticas.

\section{Considerações Finais}

Na recepção recente do cuidado de si, comumente se desconsidera que Foucault havia mudado de conceitos e de pergunta diretriz e, até mesmo, de linguagem, resistindo aos envoltórios retóricos. Seu projeto tardio e multifacetado de uma ontologia crítica do presente reflete diretamente uma experiência singular de si mesmo. Foucault expõe-se e nos põe diante de uma ontologia ainda sem cabimento em nossos esquemas estreitos de tematização do sujeito humano. Essa ontologia não endossa nem a atividade de governamento empresarial de si mesmo, nem o dandismo indiferente aos problemas que nos cercam, nem as descrições naturalizantes de nossa existência espiritual; ela mostra, antes, a possibilidade de inaugurar um agir das/nas exceções.

Seguindo, mais uma vez, Bernauer (1984), não é excessivo afirmar que nenhum filósofo ultrapassou Foucault em seu esforço contínuo e sistemático para remover a atividade filosófica do lugar de autoridade disciplinar, bem como das formas de veridicção que a afastam do lado daqueles que foram e são vitimados pelos poderes 
normalizadores, por meio dos quais nossas ciências humanas fazem falar seus conhecimentos e efetuam suas intervenções. Seria, então, casual o fato de a retomada da noção de cuidado de si estar contribuindo para uma reativação do debate sobre a formação humana na atualidade? A resposta a essa questão, ao final desta reflexão, não pode ser senão negativa. Como vimos, ao longo deste trabalho, o domínio da ética do cuidado passou a ocupar um lugar privilegiado na recepção do pensamento foucaultiano pelo campo educacional. Tudo leva a crer que a incorporação de temáticas como a espiritualidade, o cuidado de si e a parresia aponta a emergência de mais um movimento do efeito Foucault entre os educadores. No entanto, o fenômeno não deixa de ser polêmico, justamente, porque está na contramão dos movimentos hegemônicos de apropriação do pensamento de Foucault. É de fundamental importância que se façam leituras mais regulares e sistemáticas, no âmbito filosófico-educacional, para extrair suas implicações e suas consequências, sobretudo, a partir da noção de si mesmo. 


\section{Referências bibliográficas}

AGAMBEN, Giorgio. A linguagem e a morte. Um seminário sobre o lugar da negatividade. Belo Horizonte: Editora UFMG, 2006.

AGAMBEN, Giorgio. Problemas espirituais: entrevista. In: piazzaemezza (nottetempo), 23.10.2009. Disponível em: 〈http://aindanaocomecamos.blogspot.com.br/2010/11/ problemas-espirituais-giorgio-agamben.html>. Acesso em: 14 ago. 2013.

BERNAUER, James. Por uma política do espírito de Heidegger a Arendt e Foucault. Sínteses Nova Fase, Belo Horizonte, v. 21, n. 65, p. 319-336, 1994.

BRUAIRE, Claude. O ser e o espírito. São Paulo: Loyola, 2010.

CASTRILLÓN, Humberto Q. Foucault, Pedagogo? Revista Educación y Pedagogía Facultad de Educación, Universidade de Antioquia, Medellín, v. XV, n. 37, p. 201-216, sept./dic. 2003

DALBOSCO, Claudio Almir. Pragmatismo, teoria crítica e educação: ação pedagógica como mediação de significados. Campinas SP: Autores Associados, 2010.

EHRENBERG, Alexander. Le sujet cerebral. Esprit, Paris, n. 309, p. 130-155, 2004.

FIMIANI, Mariapaola. O verdadeiro amor e o cuidado comum com o mundo. In: GROS, Frédéric (Org.). Foucault: a coragem da verdade. São Paulo: Parábola Editorial, 2004. p. 89-128.

FOUCAULT, Michel. A coragem da verdade. São Paulo: Martins Fontes, 2011.

FOUCAULT, Michel. A hermenêutica do sujeito. São Paulo: Martins Fontes, 2004.

FOUCAULT, Michel. Repensar a política. Ditos e escritos VI. Rio de Janeiro: Forense Universitária, 2010.

GALLO, Silvio. Foucault: (re)pensar a educação. In: RAGO, Margareth; VEIGA-NETO, Alfredo (Org.). Figuras de Foucault. 2. ed. Belo Horizonte: Autêntica, 2008. p. 253-260.

GAZZOLA, Rachel. Platão: homem, alma, identidade (sobre o Alcibíades). In: SGANZERLA, Anor; VALVERDE, Antonio José Romera; FALABRETTI, Ericson (Org.). Natureza humana em movimento. Ensaios de antropologia filosófica. São Paulo: Paulus, 2012. p. 11-23.

KOAN, Walter. Sócrates e a Educação. O enigma da filosofia. Belo Horizonte, Autêntica, 2011.

KRAEMER, Celso. Ética e liberdade em Michel Foucault. Uma leitura de Kant. São Paulo: EDUC; FAPESP, 2011. 
LIMA VAZ, Henrique de. Platonica. São Paulo: Loyola, 2011.

MIOTTO, Marcos. O problema antropológico em Michel Foucault. Tese (Doutorado) UFSCar, São Carlos, 2011.

PEÑA, Antonio. Foucault o de la revaloración del maestro como condición de la relación pedagógica y como modelo de formación. Una mirada pedagógica a la hermenéutica del sujeto. Revista Educación y Pedagogía. Facultad de Educación, Universidade de Antioquia, Medellín, v. XV, n. 37, p. 219-232, sept.-dic. 2003.

RODRIGUES, Heliana de Barros Conde; MATTAR, Cristine Monteiro. Psicologia, filosofia, encruzilhadas, experimentações: caminhos possíveis no diálogo com Kierkegaard e Foucault. Psicologia: Ciência e Profissão, Brasília, n. 32, p. 276-291, 2012.

SLOTERDIJK, Peter. A mobilização infinita: para uma crítica da cinética política. Lisboa: Relógio D’Água Editores, 2002.

SLOTERDIJK, Peter. Extrañamiento del mundo. Valencia: Pre-Textos, 2008.

Submetido à avaliação em 17 de novembro de 2013.

Aprovado para publicação em 11 de junho de 2014. 